\title{
THE EFFECT OF MASSAGE ON WEIGHT GAIN AND SLEEP DURATION AMONG INFANTS IN KEDIRI EAST JAVA
}

\author{
Brivian Florentis Yustanta \\ School of Health Sciences Karya Husada, Kediri, East Java
}

\begin{abstract}
BACKGROUND: Massage therapy is an old and popular human touch. It has a positive effect on infant health, because it stimulates vagal nerve and hormone that improve digestion and regulate nutrient absorption. This makes the infant hungry faster, suckles more frequently, and in effect gains more weight. In addition, infant massage stimulates endorphin release that reduces pain, so that the infant feels calm, reduces crying, and sleeps more. This study aimed to determine the effect of massage on weight gain and sleep duration among infants.

SUBJECT AND METHODS: This study was a quasi experiment, before and after with control design. It was conducted in Pare, Kediri, East Java. A sample of 60 infants aged 1 to 3 months was allocated into 2 groups: (1) The experimental group consisted of 30 infants who got massaged; (2) The control group consisted of 30 infants who did not get massaged. The dependent variables were weight gain and sleep duration. Sleep duration was measured by timer and questionnaire. Weight gain was measured by a scale. The independent variable was infant massage. Weight gain between the 2 groups was analyzed using Odds Ratio and Chi Square test. Mean difference in sleep duration was tested by t-test.

RESULTS: Massaged infants were 2.49 times as many to weight gain than unmassaged infants $(\mathrm{OR}=2.49 ; \mathrm{p}=0.040)$. On average massaged infants slept longer than unmassaged infants, and it was statistically significant $(\mathrm{p}<0.001)$.

CONCLUSION: Infants massage increases weight gain and sleep duration.
\end{abstract}

Keywords: infants massage, body weight, sleep duration 